\title{
Stock assessment and management implications of an endemic fish, Oxygymnocypris stewartii, in the Yarlung Zangbo River in Tibet, China
}

\author{
Bin Huo ${ }^{1}$, Bao Shan $\mathrm{Ma}^{2}$, Cong Xin Xie ${ }^{1 *}$, You Jian Duan ${ }^{1}$, Xue Feng Yang ${ }^{1}$ and Hai Ping Huang ${ }^{1}$
}

\begin{abstract}
Background: Oxygymnocypris stewartii is an endemic species only inhabiting the middle and upper reaches of the Yarlung Zangbo River and its tributaries at altitudes above $3600 \mathrm{~m}$ in the Qinghai-Tibet Plateau and has suffered a continuous decline of population size owing to anthropogenic disturbance. However, little is known about the stock status of this species and how to protect it. In this study, we evaluated the population status of $O$. stewartii and investigated two management policies including the minimum age limits and seasonal closure in the Yarlung Zangbo River.

Results: Estimates of the total mortality rate were 0.35 year $^{-1}$ for females and 0.65 year $^{-1}$ for males. The natural mortality rates were estimated as 0.10 and 0.22 year $^{-1}$ for females and 0.12 and 0.29 year $^{-1}$ for males using two empirical methods. The $O$. stewartii population may be in near full exploitation under the current harvesting strategy in the Yarlung Zangbo River, with a high chance of recruitment failure in the future. Although both minimum age limits and seasonal closure could be effective measures to conserve the $O$. stewartii stock, it was proposed that a seasonal closure was implemented each year from September to December according to the complexity of the application and the effects on the income of local fishermen and on the biological invasion.
\end{abstract}

Conclusions: The stock of $O$. stewartii may be in near full exploitation under the current harvesting strategy, with a high chance of recruitment failure in the future. Our results indicated that the imposition of the seasonal closure from September to December might be the effective measure to conserve the O. stewartii population.

Keywords: Oxygymnocypris stewartii; Per-recruit; Seasonal closure; Mortality; Conservation

\section{Background}

Due to anthropogenic disturbance, many natural aquatic resources have suffered severe decline in abundance and yields (Dichmont et al. 2000; Hutchings and Lamberth 2002; Pauly et al. 2002; Myers and Worm 2003) and some have even been driven to the point of collapse (Hauck and Sweijd 1999; Griffiths 2000; Cowley et al. 2002). Therefore, considerable measures, including imposition of minimum captured age, protected areas, as well as closed seasons and areas in which harvesting may not take place, were implemented to better manage natural aquatic resources

\footnotetext{
* Correspondence: xiecongxin@mail.hzau.edu.cn

${ }^{1}$ College of Fisheries, Huazhong Agricultural University, Wuhan, Hubei 430070, China

Full list of author information is available at the end of the article
}

(Ye 1998; Turpie et al. 2000; Pradervand and Baird 2002; Sun et al. 2005; Govender et al. 2006).

With lack of long-term catch data and little knowledge on the spawner biomass recruit relationship, per-recruit analysis provides an alternative method to assess fish stocks for which there is some information on growth and mortality (Beverton and Holt 1957; Ricker 1975; Quinn and Deriso 1999). Among the per-recruit models, spawning stock biomass per recruit (SSBR) analyses are often employed to establish long-term management strategies to keep or recover the reproductive capacity of the population (Gabriel et al. 1989; Goodyear 1993).

Management strategies of fisheries may be established based on biological, sociological, or economic objectives. To achieve the objectives including the maximum long- 
term catch and socio-economic considerations (e.g., maximizing jobs), the biological approach will often lead to higher fishing levels and corresponding lower yields. Therefore, fisheries managers require estimates of harvest levels that provide maximum long-term yield as well as those at which the risk of stock depletion is low (Griffiths 1997). For many fish populations, there is insufficient information available to determine optimal harvesting policies. Much attention has therefore been given in the literature to determining biological reference points (BRPs) that can be readily calculated from available information (Quinn and Deriso 1999). These BRPs are usually fishing mortalities or abundance levels (thresholds) and may be specified either as a target for optimal harvesting or a danger zone to be avoided (Leaman 1993).

Oxygymnocypris stewartii (family Cyprinidae, subfamily Schizothoracinae) is one of the large predatory freshwater cyprinids distributed in the middle and upper reaches of the Yarlung Zangbo River and its tributaries at altitudes above $3600 \mathrm{~m}$ in the Qinghai-Tibet Plateau (Wu and Wu 1992; Chen and Cao 2000). Not only are O. stewartii important to local commercial fisheries, they are also one of the most ecologically important species structuring their aquatic ecosystems, mainly owing to their relatively large size and predatory nature. The field investigation found that this species was preferentially captured from September to December and local fishing communities targeted this species primarily using gill nets and traps. In winter, the preferred fishing methods are set gill nets, while drift gill nets are prone to being used for other seasons, and more rarely the traps are used to capture the fry. This species was characterized by slow growth, a long life-span, late maturation, and once-a-year spawning during February to April (Huo et al. 2012, 2013), which made it particularly sensitive to anthropogenic disturbance. Recently, overexploitation and biological invasions, including those of Carassius auratus and Pseudorasbora parva, have caused the $O$. stewartii population to rapidly decline. This species is listed in the IUCN Red List of Threatened Species as a near threatened fish ( $\mathrm{Ng} \mathrm{2010);} \mathrm{nevertheless,} \mathrm{currently}$ the O. stewartii fishery is unregulated. Scarce stock information hinders the management for this species population. Thus, to collect critical information for this stock, our specific objectives were to (1) estimate the sex-specific mortalities, (2) evaluate the population status of O. stewartii in the Yarlung Zangbo River, and (3) investigate two management policies including the minimum age limits and seasonal closure for the $O$. stewartii stock using the per-recruit model.

\section{Methods}

\section{Ethics statement}

This study was conducted according to "Instructive notions with respect to caring for laboratory animals," issued by the Ministry of Science and Technology of the People's Republic of China. All researchers had received appropriate training before performing animal studies.

\section{Sample collection}

A total of 579 individuals were monthly collected using gill nets (mesh sizes 4, 6, 8, 12, and $18 \mathrm{~cm}$ ) between August 2008 and August 2009 in the Yarlung Zangbo River and its tributary (Xiang Qu) (Fig. 1). Fish were euthanized with MS-222, and standard length $(S L)$ and body weight $(B W)$ were measured to the nearest $1 \mathrm{~mm}$ and 0.1 $\mathrm{g}$, respectively. Lapillus otoliths were extracted from each fish and were used for age estimation. Gender was determined by examining the gonad morphology.

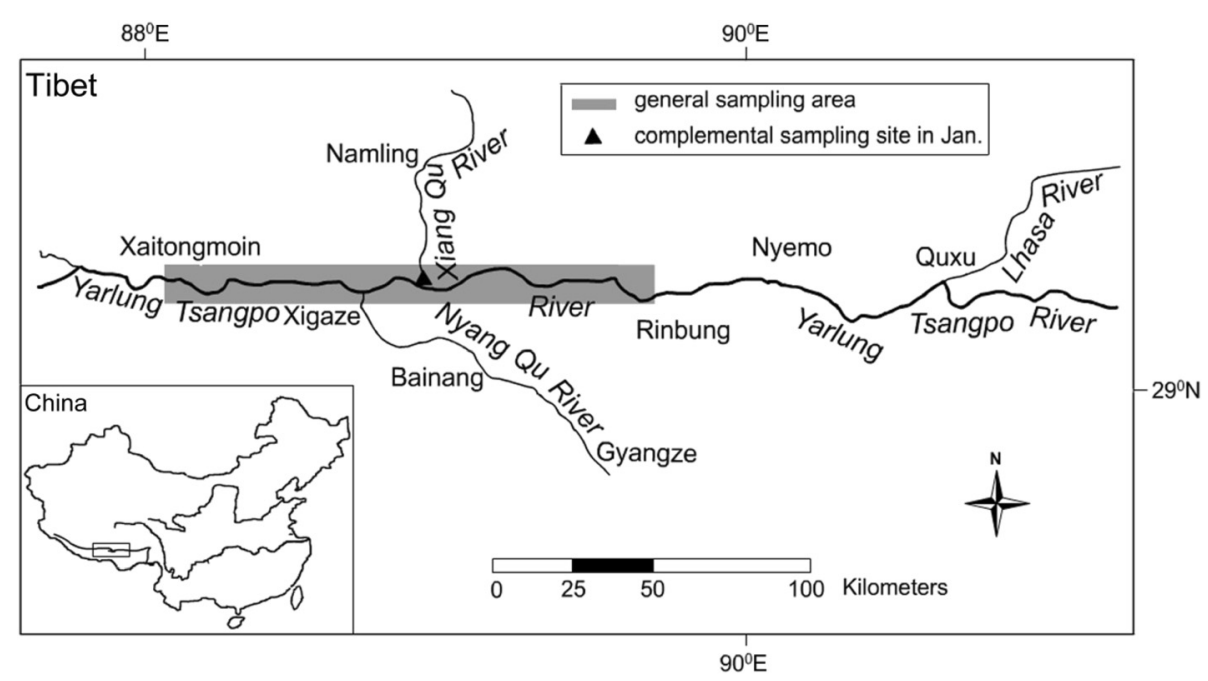

Fig. 1 The sampling locations of O. stewartii in the Yarlung Zangbo River 


\section{Growth}

Growth in length with age was modeled using the von Bertalanffy growth equation of Huo et al. (2012):

$$
\begin{aligned}
& L_{t}=526.8\{1-\exp [-0.141(t-0.491)]\} \text { for males } \\
& L_{t}=618.2\{1-\exp [-0.106(t-0.315)]\} \text { for females }
\end{aligned}
$$

where $L_{t}$ is the standard length in millimeters at age $t$. Standard length was transformed to weight in kilograms using the length-weight relationship reported by Huo et al. (2012):

$$
\begin{aligned}
& W_{t}=9.872 \times 10^{-6} L_{t}^{3.052} \text { for males } \\
& W_{t}=6.108 \times 10^{-6} L_{t}^{3.126} \text { for females }
\end{aligned}
$$

\section{Reproduction}

O. stewartii spawns just once each year from February to April. The fraction of mature fish at age $\left(G_{t}\right)$ was modeled by the logistic function published by Huo et al. (2013):

$$
\begin{aligned}
& G_{t}=\frac{1}{1+e^{-1.545(t-5.1)}} \text { for males } \\
& G_{t}=\frac{1}{1+e^{-1.376(t-7.3)}} \text { for females }
\end{aligned}
$$

\section{Mortality}

Instantaneous total annual mortality $(Z)$, for each sex, was estimated from age-based catch curves (Ricker 1975; Quinn and Deriso 1999; Smith et al. 2012). The instantaneous natural mortality $(M)$ was estimated using two empirical equations (Then et al. 2014):

$$
\begin{aligned}
& M=4.899 t_{\max }^{-0.916} \\
& M=4.118 k^{0.73} L_{\infty}^{-0.33}
\end{aligned}
$$

where $t_{\max }$ is the longevity of $O$. stewartii, estimated at 29 years for females and 22 years for males using Eq. (9); $L_{\infty}$ and $k$ are derived from Eqs. (1) and (2). The current instantaneous fishing mortality rate $\left(F_{\text {current }}\right)$ was calculated as $Z-M$. The estimates of $M$ and $F$ were assumed to be constant and independent of age.

\section{Per-recruit analysis}

Two variables, the spawning potential ratio (SPR) and yield per recruit (YPR), were calculated to assess the status of the O. stewartii stock for various fishing mortalities ranging from 0 to large values (Goodyear 1993; Quinn and Deriso 1999). The traditional per-recruit model was modified to evaluate the effects of closed seasons on SPR and YPR, which was achieved by assuming a time step of 1 month in the per-recruit model. SPR and YPR models were developed separately for each sex.
The maximum life-span $\left(t_{\max }\right)$ of O. stewartii was calculated using the empirical relationship of Taylor (1958):

$$
t_{\max }=t_{0}+\frac{2.996}{k}
$$

where $t_{0}$ and $k$ are derived from Eqs. (1) and (2).

The SPR was calculated using the following equations:

$$
\begin{aligned}
& \mathrm{SPR}=\frac{\mathrm{SSBR}_{\mathrm{F}}}{\mathrm{SSBR}_{\mathrm{F}=0}} \\
& \mathrm{SSBR}=\frac{\mathrm{SSB}}{R}=\sum_{t=t_{\mathrm{r}}}^{t_{\max }} \exp \left(\left(-F S_{t} A_{t}-M\right)\left(t-t_{\mathrm{c}}\right)\right) \\
& \times \exp \left(-M\left(t_{\mathrm{c}}-t_{\mathrm{r}}\right)\right) a L_{t}{ }^{b} G_{t}
\end{aligned}
$$

where SSB is the total spawning stock biomass; SSBR is the spawning stock biomass per recruit; $R$ is the number of recruits at age $t_{\mathrm{r}}$ and set to $1 ; \mathrm{SSBR}_{\mathrm{F}}$ is the spawning stock biomass per recruit with fishing; $\mathrm{SSBR}_{\mathrm{F}}=0$ is the spawning stock biomass per recruit without fishing; $F$ and $M$ are the fishing and natural mortality rates, respectively; $a$ and $b$ are the coefficients of the length-weight relationships and derived from Eqs. (3) and (4); $t$ is the age and the unit is in months; $L_{t}$ is the predicted mean length at age $t$ and derived from Eqs. (1) and (2); $t_{\max }$ is the maximum life-span of $O$. stewartii; $t_{\mathrm{c}}$ is the age at first capture and was taken as the age corresponding to the top of the catch curve (Griffiths 1997); $t_{\mathrm{r}}$ is the age at recruitment; and $A_{t}$ indicates whether a particular month corresponding to age $t$ is open to fishing or not. If it is open to fishing, it takes on a value of 1 or 0 otherwise. The month

Table 1 Biological parameters for per recruit analysis of

\begin{tabular}{llll} 
O. stewartii & & & \\
\hline Parameters & Female & Male & Source \\
\hline$k$ & 0.0088 month $^{-1}$ & 0.0118 month $^{-1}$ & Huo et al. (2012) \\
$t_{0}$ & 3.78 months & 5.89 months & \\
$L_{\infty}$ & $618.2 \mathrm{~mm}$ & $526.8 \mathrm{~mm}$ & \\
$a$ & 0.000006108 & 0.000009872 & \\
$b$ & 3.162 & 3.052 & \\
$Z$ & 0.0292 month $^{-1}$ & 0.0542 month $^{-1}$ & This study \\
$M$ & $0.0083-0.0183$ & $0.0100-0.0242$ & \\
& month & & \\
$F_{\text {current }}$ & $0.0108-0.0208$ & $0.0300-0.0442$ & \\
& month & & \\
$t_{r}$ & 12 months $^{-1}$ & 12 months $^{-1}$ & \\
$t_{c}$ & 60 months & 60 months & \\
$k_{\mathrm{m}}$ & 0.1147 month $^{-1}$ & 0.1288 month $^{-1}$ & Huo et al. (2013) \\
$A_{50}$ & 87.6 months & 61.2 months &
\end{tabular}

$a$ and $b$ are the coefficients of Eqs. (3) and (4); $k_{\mathrm{m}}$ and $A_{50}$ are the coefficients of Eqs. (5) and (6) 
Table 2 The different harvesting strategies for the O. stewartii stock spawning from February to April

\begin{tabular}{lll}
\hline Management policies & The age at first capture (years) & Seasonal closure \\
\hline Current policy & 5 & - \\
Policy 1 & 1 & - \\
Policy 2 & 3 & - \\
Policy 3 & 7 & - \\
Policy 4 & 1 & Feb-May \\
Policy 5 & 3 & Feb-May \\
Policy 6 & 5 & Feb-May \\
Policy 7 & 7 & Feb-May \\
Policy 8 & 1 & Sep-Dec \\
Policy 9 & 3 & Sep-Dec \\
Policy 10 & 5 & Sep-Dec \\
Policy 11 & 7 & Sep-Dec \\
\hline
\end{tabular}

when $t=t_{\mathrm{r}}$ was set to March; $G_{t}$ is derived from Eqs. (5) and (6); and $S_{t}$ is the gear selectivity at age $t$ and is assumed to be knife-edged selectivity:

$$
S_{t}= \begin{cases}0, & t<t_{\mathrm{c}} \\ 1, & t \geq t_{\mathrm{c}}\end{cases}
$$

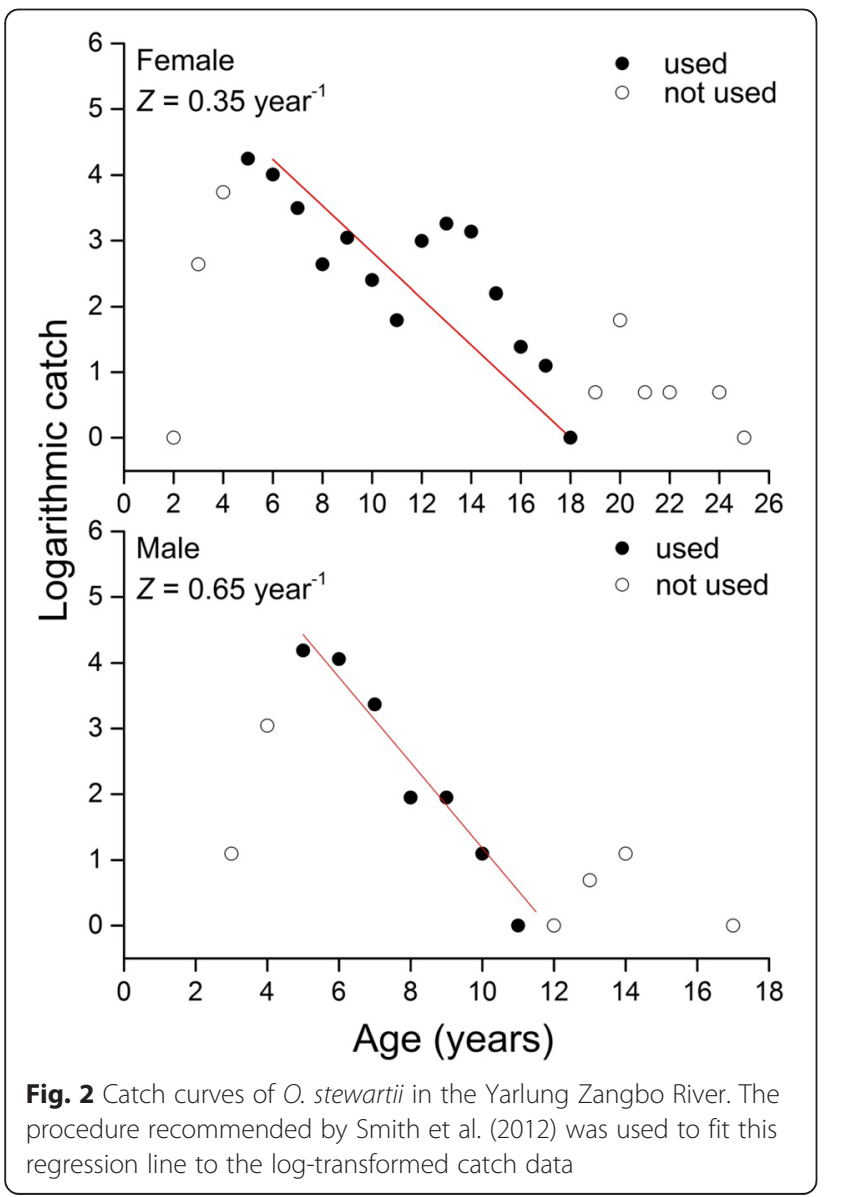

The YPR was calculated from the following formula:

$$
\begin{aligned}
\mathrm{YPR}=\frac{Y}{R}= & \sum_{t=t_{\mathrm{r}}}^{t_{\max }} \frac{F S_{t} A_{t}}{F S_{t} A_{t}+M} \exp \left(\left(-F_{s} S_{t} A_{t}-M\right)\left(t-t_{\mathrm{c}}\right)\right) \\
& \times \exp \left(-M\left(t_{\mathrm{c}}-t_{\mathrm{r}}\right)\right)\left(1-\exp \left(-F S_{t} A_{t}-M\right)\right) a L_{t}{ }^{b}
\end{aligned}
$$

where $Y$ is the total yield for a cohort throughout its life-span.

The parameters used in this study are given in Table 1. Given the difficulties in obtaining accurate estimates of natural mortality for exploited populations, the sensitivity of the per-recruit models to various estimates of $M$ was tested. Moreover, we explored the changes in YPR and SPR under different combinations of the age at first capture and fishing mortality using the isopleth plot in order to evaluate the best compromise between the conservation of $O$. stewartii population and maximizing YPR. We also simulated 11 different harvesting strategies that were

\begin{tabular}{|c|c|c|}
\hline \multirow[t]{2}{*}{ Age group (year) } & \multicolumn{2}{|c|}{ Catch (number) } \\
\hline & Female & Male \\
\hline 1 & 0 & 0 \\
\hline 2 & 1 & 0 \\
\hline 3 & 14 & 3 \\
\hline 4 & 42 & 21 \\
\hline 5 & 70 & 66 \\
\hline 6 & 56 & 58 \\
\hline 7 & 31 & 29 \\
\hline 8 & 15 & 7 \\
\hline 9 & 21 & 7 \\
\hline 10 & 11 & 3 \\
\hline 11 & 6 & 1 \\
\hline 12 & 20 & 1 \\
\hline 13 & 26 & 2 \\
\hline 14 & 23 & 3 \\
\hline 15 & 9 & 0 \\
\hline 16 & 4 & 0 \\
\hline 17 & 3 & 1 \\
\hline 18 & 1 & 0 \\
\hline 19 & 2 & 0 \\
\hline 20 & 7 & 0 \\
\hline 21 & 2 & 0 \\
\hline 22 & 2 & 0 \\
\hline 23 & 0 & 0 \\
\hline 24 & 2 & 0 \\
\hline 25 & 1 & 0 \\
\hline
\end{tabular}

Table 3 The age frequency of O. stewartii in the Yarlung Zangbo River 
different from the current state to evaluate whether the closure season is an effective conservation for the O. stewartii population. These harvesting strategies were termed policies 1-11 (Table 2).

\section{Biological reference point}

The following reference points were used to determine the current status of the $O$. stewartii stock as well as to evaluate the effectiveness of different regulations: $F_{25 \%}$ and $F_{40 \%}$ are defined as fishing mortality rates that reduce SPR to 25 and $40 \%$, respectively, when compared to an unfished state where SPR is assumed to be at a level of 100 \% (Gabriel et al. 1989; Goodyear 1993; Sun et al. 2005); $F_{\max }$ is defined as the fishing mortality rate that produces the maximum yield per recruit.

\section{Results}

\section{Mortality}

The estimates of $Z$ for female and male O. stewartii from the slope of the descending limb of the catch curve were 0.35 and 0.65 year $^{-1}$, respectively (Fig. 2, Table 3). The values of $M$ estimated by the empirical Eqs. (7) and (8) were 0.10 and 0.22 year $^{-1}$ for females and 0.12 and 0.29 year $^{-1}$ for males, respectively. The instantaneous natural mortalities of $O$. stewartii were therefore assumed to be between 0.10 and 0.22 year $^{-1}$ for females and between 0.12 and 0.29 year $^{-1}$ for males, respectively. The corresponding estimates of $F_{\text {current }}$ were 0.13 and 0.25 year $^{-1}$ for females and 0.36 and 0.53 year $^{-1}$ for males, respectively.

\section{Per-recruit analysis}

Per-recruit analysis was conducted at three alternative values of natural mortality $\left(0.10,0.17\right.$, and 0.22 year $^{-1}$ for females; 0.12, 0.21, and 0.29 year $^{-1}$ for males) within the predicted range for each gender. At the current harvesting strategy and three corresponding alternative values of $M$, the range of SPR for females was 10.93-38.14\% while that for males was $9.17-28.78 \%$, when compared to the state of no fishing (Fig. 3, Tables 4 and 5). In addition, the estimates of $F_{25 \%}$ and $F_{40 \%}$ fluctuated widely with $M$. The estimates of $F_{25 \%}$ were $0.14-0.20$ year $^{-1}$ for females and 0.22-0.45 year $^{-1}$ for males, respectively, and the estimates of $F_{40 \%}$ were $0.08-0.12$ year $^{-1}$ for females and $0.13-0.23$ year $^{-1}$ for males, respectively (Fig. 3, Tables 4 and 5).

The effects of varying the age at first capture on the YPR and SPR under three corresponding values of $M$ for each gender are demonstrated in Figs. 4 and 5. The YPR increased rapidly at low levels of $F$ for most of the range of $t_{\mathrm{c}}$. Increasing the $t_{\mathrm{c}}$ to between 6 and 13 years for females and between 5 and 9 years for males would have relatively little impact on the YPR under almost any level of fishing, when compared to the current YPR (Fig. 4). Moreover, the SPR would be maintained above $25 \%$ under almost all ranges of fishing mortality, when enhancing the

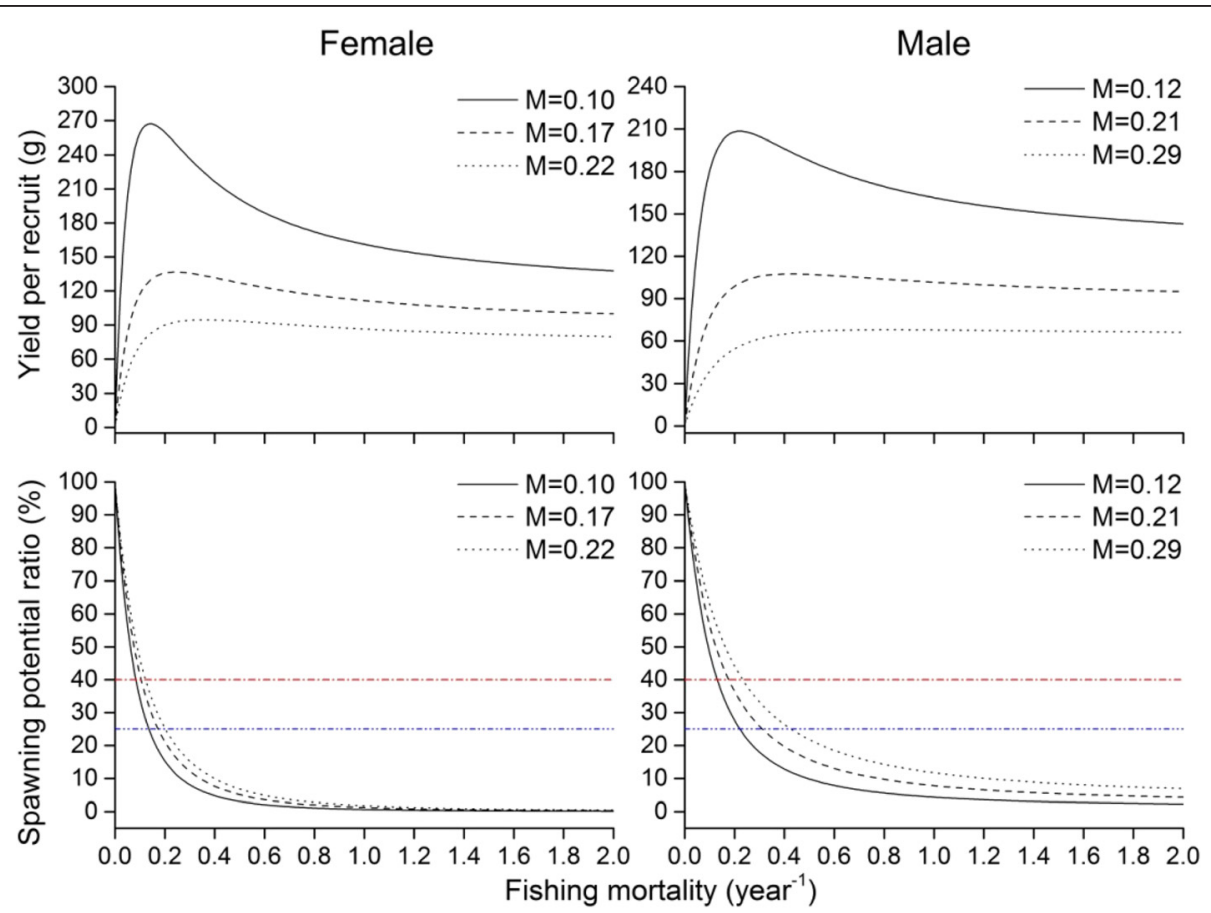

Fig. 3 Yield per recruit and spawning potential ratio curves for 0 . stewartii by sex. Yield per recruit and spawning potential ratio curves for 0 . stewartii by sex under a range of fishing mortality rates and the current harvesting strategy of the first age at capture at 5 years and no closed season. The dashed-dotted-dotted blue and dashed-dotted red lines represent SPR at 25 and $40 \%$, respectively 
Table 4 Estimates of YPR, SPR, and reference points under different harvesting strategies for female O. stewartii stock

\begin{tabular}{|c|c|c|c|c|c|c|c|c|c|}
\hline Management policy & $M\left(\right.$ year $\left.^{-1}\right)$ & $F_{\max }\left(\right.$ year $\left.^{-1}\right)$ & $F_{25 \%}\left(\right.$ year $\left.^{-1}\right)$ & $F_{40 \%}\left(\right.$ year $\left.^{-1}\right)$ & $\mathrm{YPR}_{\text {current }}(\mathrm{g})$ & $\mathrm{YPR}_{\max }(\mathrm{g})$ & $\mathrm{YPR}_{25 \%}(\mathrm{~g})$ & $\mathrm{YPR}_{40 \%}(\mathrm{~g})$ & $\mathrm{SPR}_{\text {current }}(\%)$ \\
\hline \multirow[t]{3}{*}{ Current policy } & 0.10 & 0.14 & 0.14 & 0.08 & 248.33 & 267.24 & 267.24 & 245.84 & 10.93 \\
\hline & 0.17 & 0.24 & 0.17 & 0.11 & 134.65 & 136.77 & 133.71 & 121.18 & 23.89 \\
\hline & 0.22 & 0.36 & 0.20 & 0.12 & 79.90 & 94.57 & 89.85 & 77.56 & 38.14 \\
\hline \multirow[t]{3}{*}{ Policy 1} & 0.10 & 0.08 & 0.09 & 0.06 & 111.41 & 188.93 & 188.27 & 182.41 & 4.02 \\
\hline & 0.17 & 0.11 & 0.11 & 0.07 & 79.97 & 88.79 & 88.76 & 83.62 & 11.63 \\
\hline & 0.22 & 0.13 & 0.12 & 0.08 & 57.95 & 57.95 & 57.89 & 54.04 & 22.68 \\
\hline \multirow[t]{3}{*}{ Policy 2} & 0.10 & 0.10 & 0.11 & 0.07 & 176.81 & 224.78 & 224.59 & 213.60 & 6.63 \\
\hline & 0.17 & 0.15 & 0.13 & 0.08 & 110.31 & 111.21 & 110.48 & 99.46 & 16.67 \\
\hline & 0.22 & 0.20 & 0.15 & 0.09 & 72.32 & 75.49 & 74.13 & 64.80 & 29.41 \\
\hline \multirow[t]{3}{*}{ Policy 3} & 0.10 & 0.20 & 0.18 & 0.11 & 306.80 & 309.17 & 308.56 & 288.25 & 17.83 \\
\hline & 0.17 & 0.44 & 0.26 & 0.14 & 144.54 & 158.42 & 154.04 & 134.79 & 33.98 \\
\hline & 0.22 & 0.85 & 0.33 & 0.18 & 77.65 & 108.27 & 102.07 & 88.19 & 49.18 \\
\hline \multirow[t]{3}{*}{ Policy 4} & 0.10 & 0.08 & 0.09 & 0.06 & 81.08 & 171.45 & 169.03 & 168.10 & 4.16 \\
\hline & 0.17 & 0.09 & 0.11 & 0.07 & 58.16 & 72.95 & 71.74 & 71.13 & 11.87 \\
\hline & 0.22 & 0.10 & 0.12 & 0.08 & 42.16 & 43.39 & 42.82 & 42.49 & 22.98 \\
\hline \multirow[t]{3}{*}{ Policy 5} & 0.10 & 0.09 & 0.11 & 0.07 & 132.28 & 202.00 & 199.60 & 196.51 & 6.72 \\
\hline & 0.17 & 0.12 & 0.13 & 0.08 & 82.48 & 89.01 & 88.59 & 84.76 & 16.82 \\
\hline & 0.22 & 0.13 & 0.15 & 0.09 & 54.12 & 54.12 & 53.81 & 51.30 & 29.59 \\
\hline \multirow[t]{3}{*}{ Policy 6} & 0.10 & 0.13 & 0.14 & 0.08 & 218.09 & 250.13 & 249.32 & 235.28 & 10.95 \\
\hline & 0.17 & 0.18 & 0.17 & 0.11 & 118.22 & 118.22 & 118.12 & 110.78 & 23.92 \\
\hline & 0.22 & 0.22 & 0.20 & 0.12 & 70.17 & 75.59 & 75.40 & 68.53 & 38.18 \\
\hline \multirow[t]{3}{*}{ Policy 7} & 0.10 & 0.20 & 0.18 & 0.11 & 306.80 & 309.17 & 308.56 & 288.25 & 17.83 \\
\hline & 0.17 & 0.44 & 0.26 & 0.14 & 144.54 & 158.42 & 154.04 & 134.79 & 33.98 \\
\hline & 0.22 & 0.85 & 0.33 & 0.18 & 77.65 & 108.27 & 102.07 & 88.19 & 49.18 \\
\hline \multirow[t]{3}{*}{ Policy 8} & 0.10 & 0.07 & 0.16 & 0.08 & 77.07 & 139.49 & 108.13 & 138.98 & 20.75 \\
\hline & 0.17 & 0.10 & - & 0.13 & 55.32 & 60.90 & - & 59.85 & 34.53 \\
\hline & 0.22 & 0.14 & - & 0.22 & 40.08 & 40.13 & - & 37.93 & 47.04 \\
\hline \multirow[t]{3}{*}{ Policy 9} & 0.10 & 0.09 & 0.19 & 0.09 & 120.18 & 161.73 & 135.40 & 161.73 & 22.08 \\
\hline & 0.17 & 0.16 & - & 0.15 & 74.99 & 75.15 & - & 75.10 & 37.09 \\
\hline & 0.22 & 0.36 & - & 0.28 & 49.16 & 55.26 & - & 54.89 & 50.47 \\
\hline \multirow[t]{3}{*}{ Policy 10} & 0.10 & 0.11 & 0.23 & 0.11 & 154.97 & 181.70 & 158.46 & 181.70 & 24.26 \\
\hline & 0.17 & 1.09 & - & 0.19 & 84.02 & 103.63 & - & 84.43 & 40.75 \\
\hline & 0.22 & 1.21 & - & 0.41 & 49.86 & 81.39 & - & 68.31 & 54.90 \\
\hline \multirow[t]{3}{*}{ Policy 11} & 0.10 & 5.01 & 0.32 & 0.13 & 152.87 & 218.67 & 137.21 & 185.53 & 27.69 \\
\hline & 0.17 & 5.62 & - & 0.26 & 71.98 & 141.44 & - & 69.85 & 45.75 \\
\hline & 0.22 & 6.30 & - & 2.72 & 38.69 & 104.15 & - & 98.54 & 60.38 \\
\hline
\end{tabular}

-: no data

$t_{\mathrm{c}}$ to 12 years for females and 9 years for males (Fig. 5). Thus, setting the $t_{\mathrm{c}}$ at 12 years for females and 9 years for males could ensure that the SPR was above the threshold at almost any level of fishing with relatively little impact on YPR regardless of $M$.

It is apparent that an introduction of the seasonal closure helps to conserve the $O$. stewartii population at the expense of decreasing the YPR. The introduction of the seasonal closure caused the YPR to significantly decline, regardless of when the closure season is set (Figs. 6 and 7, Tables 4 and 5). However, the SPR is related to when the closure season is set (Figs. 8 and 9, Tables 4 and 5). Based on a scenario of closed season from February to May, significantly increasing the SPR is dependent on both the age at first capture and the level of fishing mortality. On the other hand, the SPR can be dramatically increased 
Table 5 Estimates of YPR, SPR, and reference points under different harvesting strategies for male O. stewartii stock

\begin{tabular}{|c|c|c|c|c|c|c|c|c|c|}
\hline Management policy & $M\left(\right.$ year $\left.^{-1}\right)$ & $F_{\max }\left(\right.$ year $\left.^{-1}\right)$ & $F_{25 \%}\left(\right.$ year $\left.^{-1}\right)$ & $F_{40 \%}\left(\right.$ year $\left.^{-1}\right)$ & $\mathrm{YPR}_{\text {current }}(\mathrm{g})$ & $\mathrm{YPR}_{\max }(\mathrm{g})$ & $\mathrm{YPR}_{25 \%}(\mathrm{~g})$ & $\mathrm{YPR}_{40 \%}(\mathrm{~g})$ & $\mathrm{SPR}_{\text {current }}(\%)$ \\
\hline \multirow[t]{3}{*}{ Current policy } & 0.12 & 0.22 & 0.22 & 0.13 & 185.50 & 208.42 & 208.42 & 195.64 & 9.17 \\
\hline & 0.21 & 0.43 & 0.31 & 0.18 & 107.44 & 107.46 & 106.07 & 96.16 & 17.92 \\
\hline & 0.29 & 0.82 & 0.45 & 0.23 & 63.84 & 67.94 & 65.92 & 57.15 & 28.78 \\
\hline \multirow[t]{3}{*}{ Policy 1} & 0.12 & 0.11 & 0.13 & 0.08 & 44.95 & 134.78 & 132.59 & 130.90 & 1.15 \\
\hline & 0.21 & 0.14 & 0.15 & 0.09 & 37.31 & 63.80 & 63.61 & 60.06 & 3.19 \\
\hline & 0.29 & 0.17 & 0.17 & 0.11 & 30.53 & 37.78 & 37.78 & 35.50 & 7.03 \\
\hline \multirow[t]{3}{*}{ Policy 2} & 0.12 & 0.15 & 0.16 & 0.10 & 110.23 & 168.97 & 168.58 & 161.56 & 3.31 \\
\hline & 0.21 & 0.22 & 0.20 & 0.12 & 76.44 & 85.11 & 84.91 & 77.55 & 7.69 \\
\hline & 0.29 & 0.32 & 0.24 & 0.14 & 53.29 & 53.48 & 52.61 & 46.15 & 14.43 \\
\hline \multirow[t]{3}{*}{ Policy 3} & 0.12 & 0.36 & 0.39 & 0.20 & 239.59 & 242.55 & 242.41 & 230.99 & 20.28 \\
\hline & 0.21 & 1.24 & 0.86 & 0.32 & 115.91 & 121.65 & 121.18 & 110.15 & 34.21 \\
\hline & 0.29 & - & 3.36 & 0.58 & 58.68 & 74.03 & 72.77 & 65.25 & 48.42 \\
\hline \multirow[t]{3}{*}{ Policy 4} & 0.12 & 0.09 & 0.13 & 0.08 & 16.82 & 112.58 & 106.44 & 111.67 & 4.18 \\
\hline & 0.21 & 0.11 & 0.16 & 0.10 & 13.96 & 45.42 & 42.06 & 45.34 & 8.63 \\
\hline & 0.29 & 0.12 & 0.21 & 0.12 & 11.42 & 22.41 & 19.17 & 22.41 & 14.92 \\
\hline \multirow[t]{3}{*}{ Policy 5} & 0.12 & 0.12 & 0.16 & 0.10 & 44.09 & 137.97 & 132.60 & 136.60 & 5.61 \\
\hline & 0.21 & 0.14 & 0.21 & 0.13 & 30.58 & 57.47 & 53.85 & 57.30 & 11.62 \\
\hline & 0.29 & 0.16 & 0.28 & 0.16 & 21.32 & 28.95 & 25.29 & 28.95 & 19.84 \\
\hline \multirow[t]{3}{*}{ Policy 6} & 0.12 & 0.18 & 0.22 & 0.13 & 127.27 & 183.02 & 180.24 & 178.21 & 9.76 \\
\hline & 0.21 & 0.24 & 0.32 & 0.18 & 73.72 & 82.36 & 80.35 & 80.48 & 18.83 \\
\hline & 0.29 & 0.30 & 0.46 & 0.24 & 43.80 & 44.32 & 41.67 & 43.76 & 29.95 \\
\hline \multirow[t]{3}{*}{ Policy 7} & 0.12 & 0.36 & 0.39 & 0.20 & 239.59 & 242.55 & 242.41 & 230.99 & 20.28 \\
\hline & 0.21 & 1.24 & 0.87 & 0.32 & 115.91 & 121.65 & 121.22 & 110.15 & 34.21 \\
\hline & 0.29 & - & 3.36 & 0.58 & 58.68 & 74.03 & 72.77 & 65.25 & 48.42 \\
\hline \multirow[t]{3}{*}{ Policy 8} & 0.12 & 0.10 & - & 0.16 & 39.45 & 91.88 & - & 85.69 & 29.36 \\
\hline & 0.21 & 0.16 & - & 0.33 & 32.75 & 45.03 & - & 38.52 & 37.85 \\
\hline & 0.29 & 0.22 & - & 0.61 & 26.79 & 29.40 & - & 19.38 & 43.74 \\
\hline \multirow[t]{3}{*}{ Policy 9} & 0.12 & 0.15 & - & 0.20 & 94.35 & 113.46 & - & 111.48 & 30.98 \\
\hline & 0.21 & 0.40 & - & 0.51 & 65.42 & 65.51 & - & 64.87 & 41.22 \\
\hline & 0.29 & 0.52 & - & 1.13 & 45.61 & 46.98 & - & 41.90 & 49.28 \\
\hline \multirow[t]{3}{*}{ Policy 10} & 0.12 & 1.06 & - & 0.29 & 139.67 & 149.43 & - & 131.09 & 35.28 \\
\hline & 0.21 & 1.27 & - & 1.87 & 80.90 & 96.46 & - & 95.05 & 48.72 \\
\hline & 0.29 & 1.57 & - & - & 48.06 & 66.16 & - & - & 59.82 \\
\hline \multirow[t]{3}{*}{ Policy 11} & 0.12 & 5.46 & - & 1.11 & 107.30 & 208.46 & - & 145.79 & 41.86 \\
\hline & 0.21 & - & - & - & 51.91 & 119.64 & - & - & 58.44 \\
\hline & 0.29 & - & - & - & 26.28 & 74.03 & - & - & 71.60 \\
\hline
\end{tabular}

-: no data

regardless of the level of fishing mortality and the age at first capture when assuming a closed season from September to December.

\section{Discussion}

Biological reference points such as $F_{\max }, F_{25 \%}$, and $F_{40 \%}$ have often been used to develop fishery management strategies. Several authors have advocated designating
$F_{40 \%}$ as a target reference point and $F_{25 \%}$ as a threshold reference point in order to obtain near optimal yields while insuring against stock collapse (Hildén 1993; Leaman 1993; Mace and Sissenwine 1993; Rivard and Maguire 1993; Mace 1994; Griffiths 1997; Kirchner 2001; Sun et al. 2005). Our results based on per-recruit analyses suggest that the current fishing mortalities for each sex population are constantly higher than the corresponding 


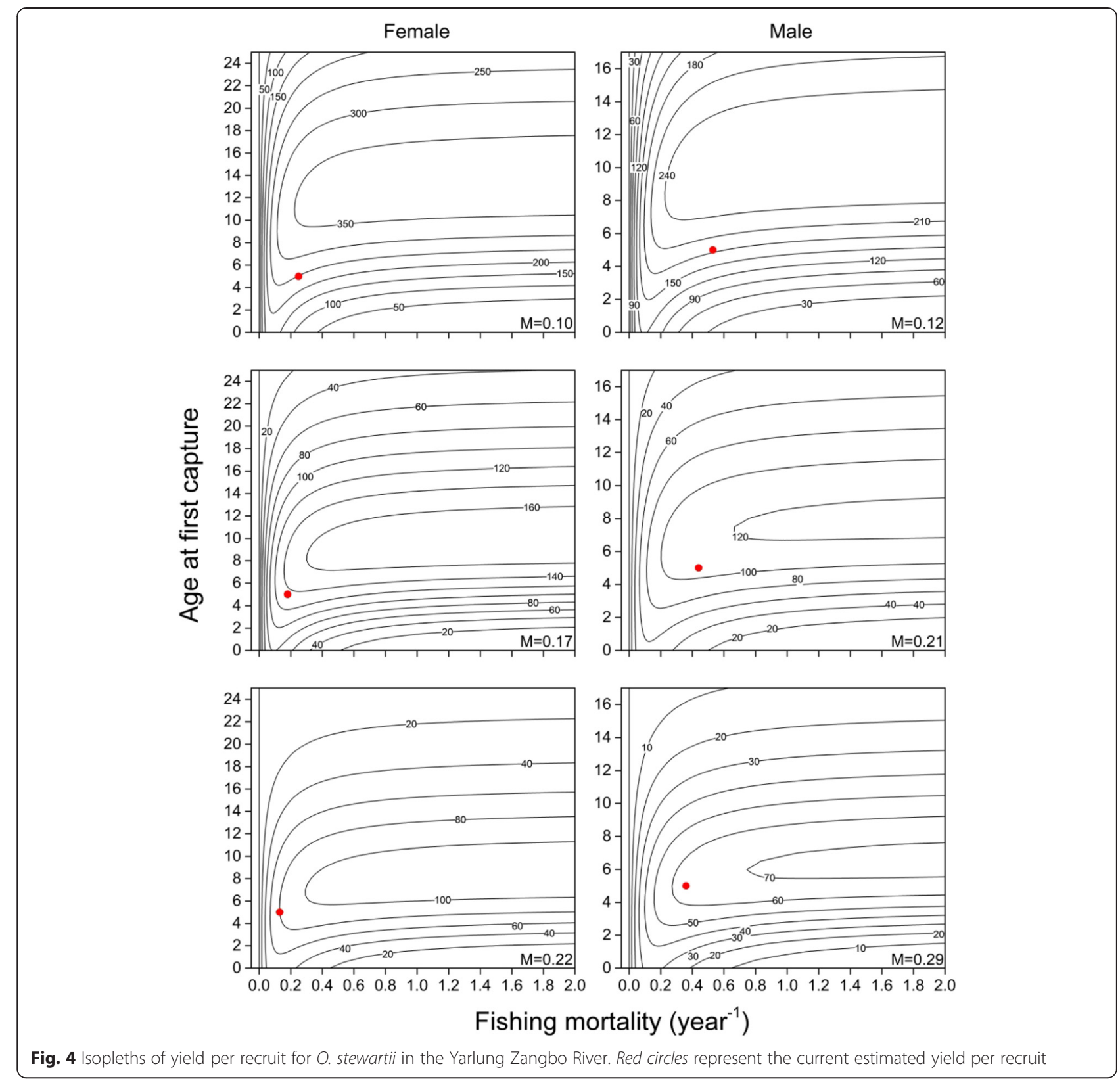

threshold reference point $F_{25 \%}$ at the lower and intermedia values of $M$, while the current fishing mortalities are lower than the corresponding threshold reference point $F_{25 \%}$ but higher than the corresponding target reference point $F_{40 \%}$ at the higher values of $M$, which indicates that the stock status of $O$. stewartii in the Yarlung Zangbo River is sensitive to the estimated values of $M$. However, the evaluation of various empirical estimators, implemented by Then et al. (2014), shows clearly that Eq. (7) is both the best and a sufficient predictor of $M$, indicating that the estimated higher value of $M$ may be more reliable than the others. In addition, Smith et al. (2012) reported that the weighted regression estimator of fishing mortality (derived from $Z$ ) was always negatively biased, indicating that the estimated $F_{\text {current }}$ might be underestimated. Therefore, the O. stewartii population may be in near full exploitation in the Yarlung Zangbo River.

Imposition of a closed season during the breeding period is only effective under three circumstances: (1) if fishing disturbs and reduces reproduction of individuals that are not captured, (2) if the target species aggregates to breed and becomes vulnerable to capture, and (3) if the closed season achieves a reduction of annual fishing effort (Arendse et al. 2007). Our results indicated that imposition of the closed season during the spawning season (February to May) was not effective, while that during 


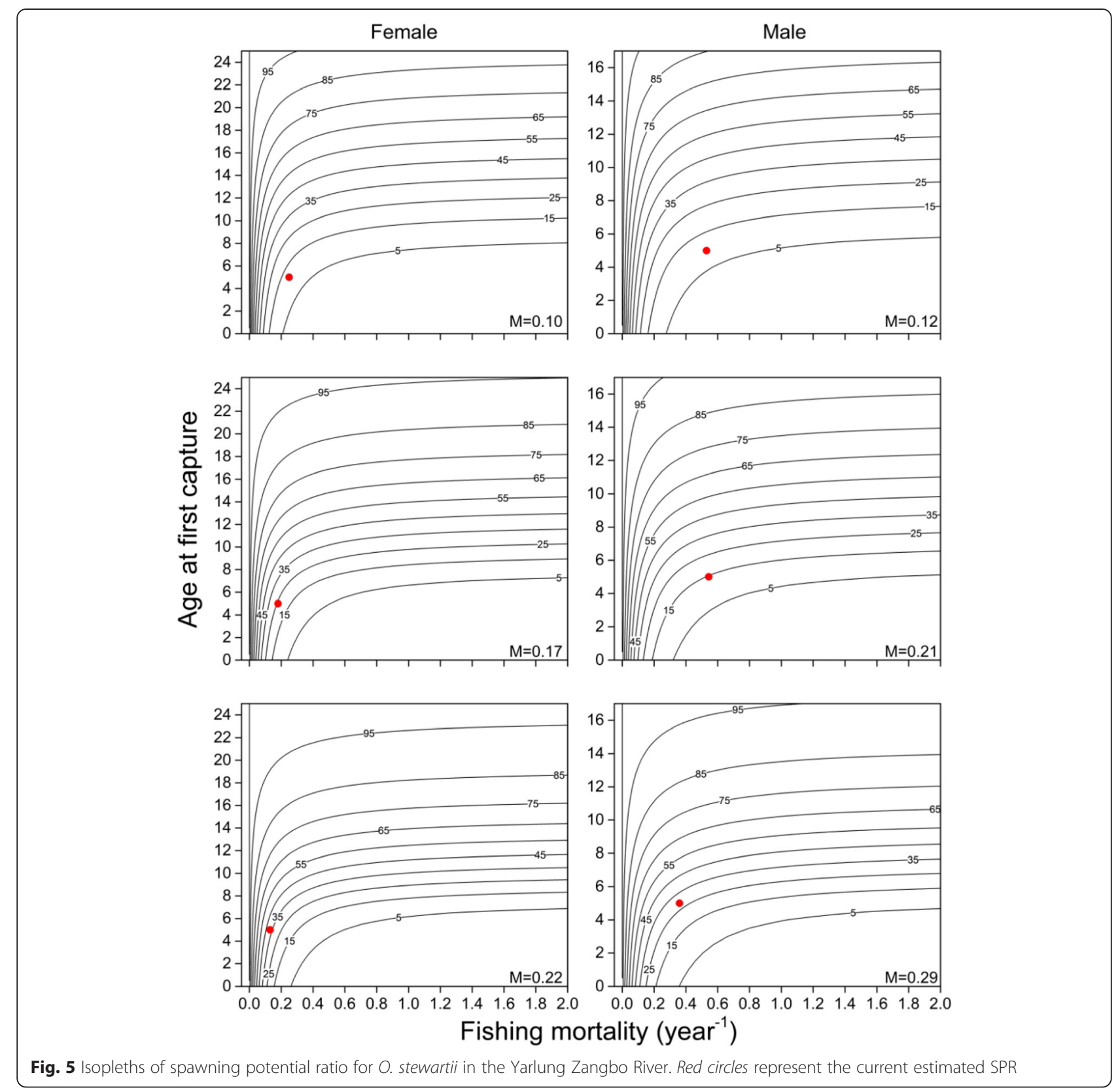

September to December was effective. Our field survey found that $O$. stewartii aggregated to lay eggs and became vulnerable to capture during the spawning season. However, there were no spawning sites in our sampling locations. Moreover, $O$. stewartii is intensively captured during September to December every year, which corresponded to the gonad development period. Thus, the imposition of the closed season during September to December could reduce the annual fishing effort and help to conserve the O. stewartii stock.

Although increasing the age at first capture and introducing the closed season could be effective measures to conserve the $O$. stewartii stock, we prefer the imposition of the closed season to manage its population based on three reasons: (1) Compared with increasing the age at first capture, the closed season could be easily implemented and monitored, especially for the vast territory of Tibet. (2) The field survey found that the local people had an important custom that they would buy a lot of all kinds of small fish, including juveniles of O. stewartii, to release back to the river. Thus, the income of local fishermen is derived from both the adult fish and small fish. If the measure of increasing the age at first capture was carried out, part of the income from the sales of small fish would be reduced. If the closed season was implemented, the income from the sales of adult fish 


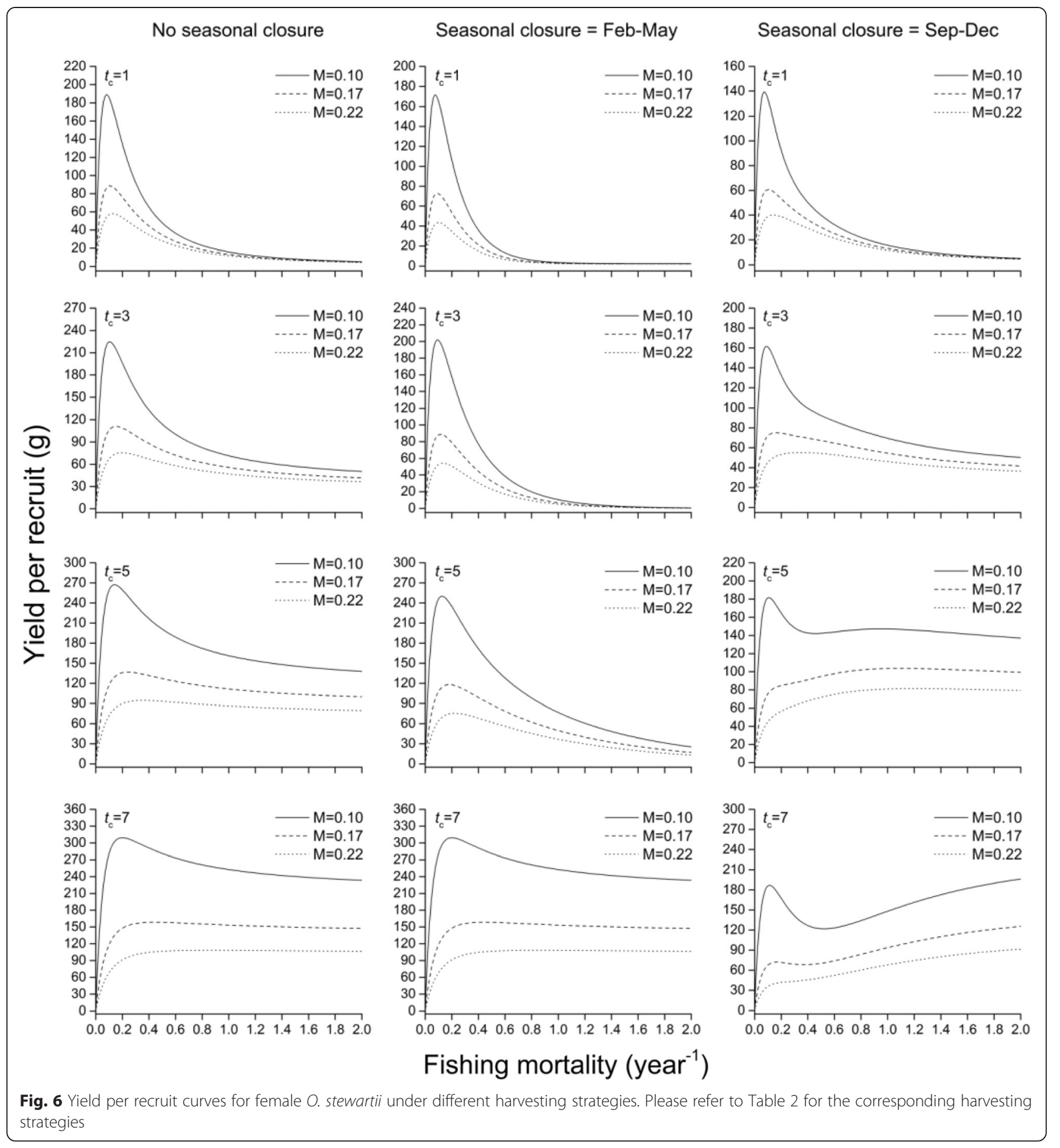

would be decreased. Therefore, regardless of which measures are taken, they have similar impact on the income of local fishermen. (3) By increasing the age at first capture, the catch of endemic small fish would likely decline dramatically, which likely will cause local people to switch to releasing the alien small fish back to the river. Invasive species usually threaten the survival of the native species due to competition for habitat and dietary resources.
Our results based on the per-recruit analysis can be misleading if the assumptions of the analysis and its various inputs, namely growth parameters, sampling bias, fishing, and natural mortality, are not made explicit. First of all, the per-recruit analysis is heavily affected by von Bertalanffy growth parameters. A meaningful estimate of growth parameters is related to age and size inputs. Compared with other age materials, pre-analyses showed that lapillus, which provided the age input for 


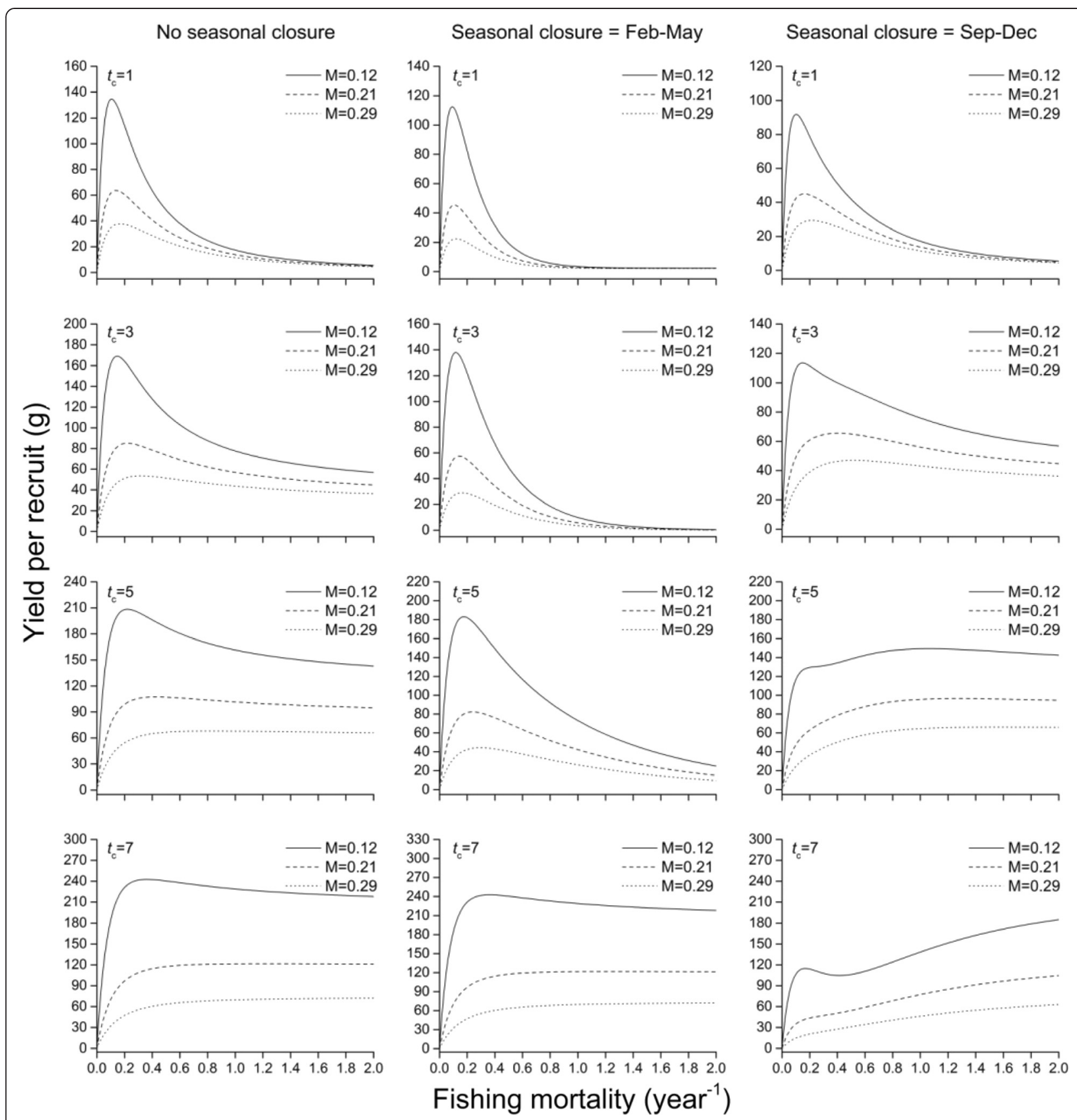

Fig. 7 Yield per recruit curves for male O. stewartii under different harvesting strategies. Please refer to Table 2 for the corresponding harvesting strategies

the von Bertalanffy growth model, is the most precise and accurate structure for age estimation. In addition, growth model estimates are greatly influenced by the lack of very young or old individuals (Cailliet and Goldman 2004). Huo et al. (2012) reported that the size composition including enough juveniles $(<100 \mathrm{~mm} S L)$ and old individuals $(>500 \mathrm{~mm} \mathrm{SL}$ ) provided a reliable estimate of growth parameters. Secondly, we acknowledge that the gill net has its own sampling bias. However, to reduce the sampling bias, the gill nets with multiple mesh sizes were deployed to collect $O$. stewartii, and the ranges in standard length and age extended broadly indicating that sampling bias did not drastically appear. Thirdly, our results are only valid if natural and fishing mortality rates used in our analysis are representative of the long-term situation. Our field investigations find that the catches of this species fluctuate little in recent years and the possibility for this trend may be continuous in 


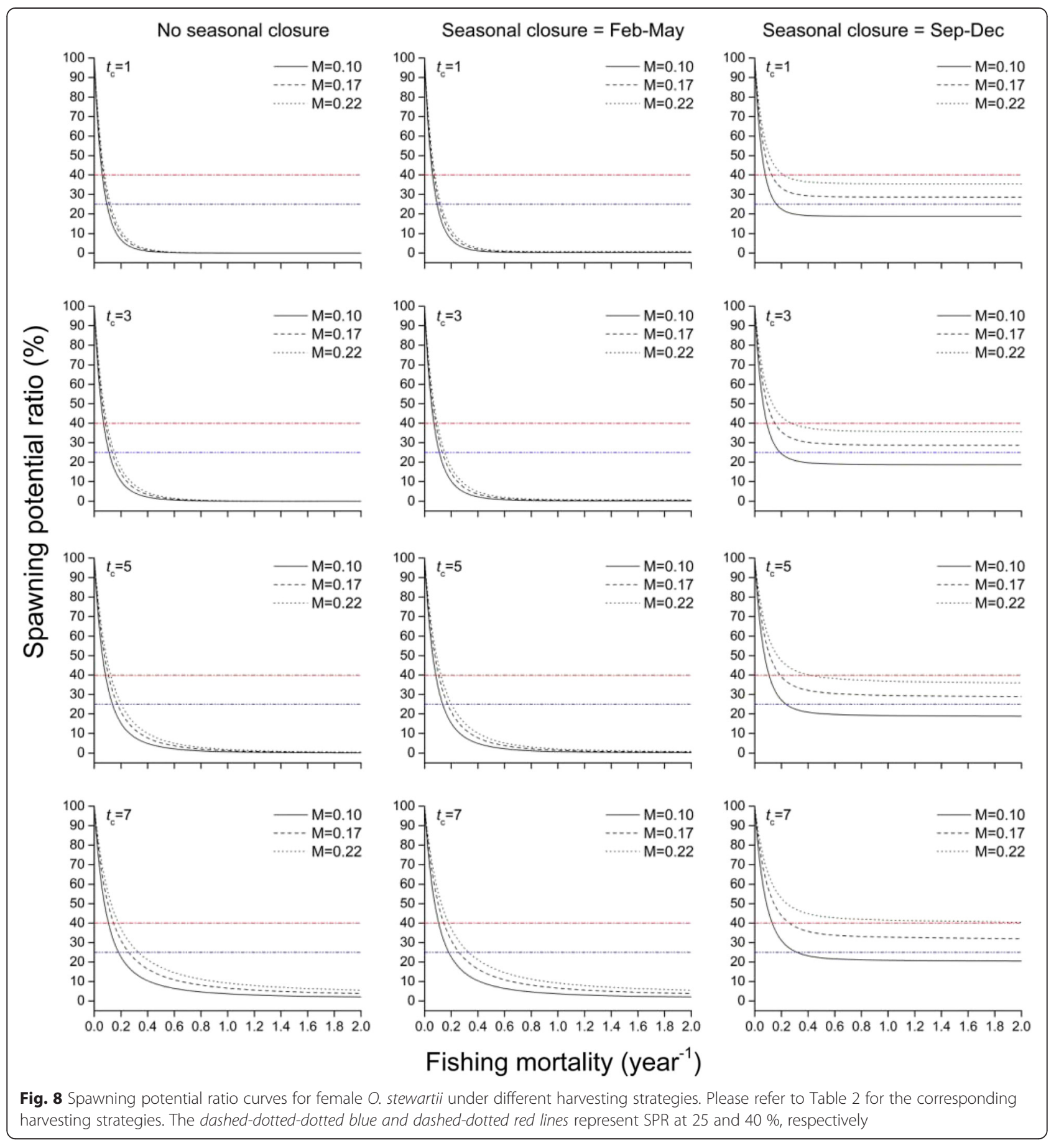

the future. Thus, it is possible that the age structure of the population may remain the same in the future as we have documented here. Fourthly, the natural mortality is generally difficult to be estimated reliably and directly. By direct, the natural mortality prefers to be estimated using information strictly pertaining to the stock of interest. However, direct estimation methods of $M$ are often data intensive, thus limiting their application to relatively data-rich stocks (Then et al. 2014). For data-poor stocks, indirect or empirical equations are often used to estimate $M$. Although these empirical methods are less reliable than their data-rich counterparts, a consensus is that empirical methods are useful and very important particularly for the data-poor stocks. In our study, we evaluated the sensitivity of the per-recruit models to various estimates of $M$ within the range of plausible values for $M$ for the $O$. stewartii stock by applying two empirical methods, which represent both the best and sufficient predictors of $M$. 


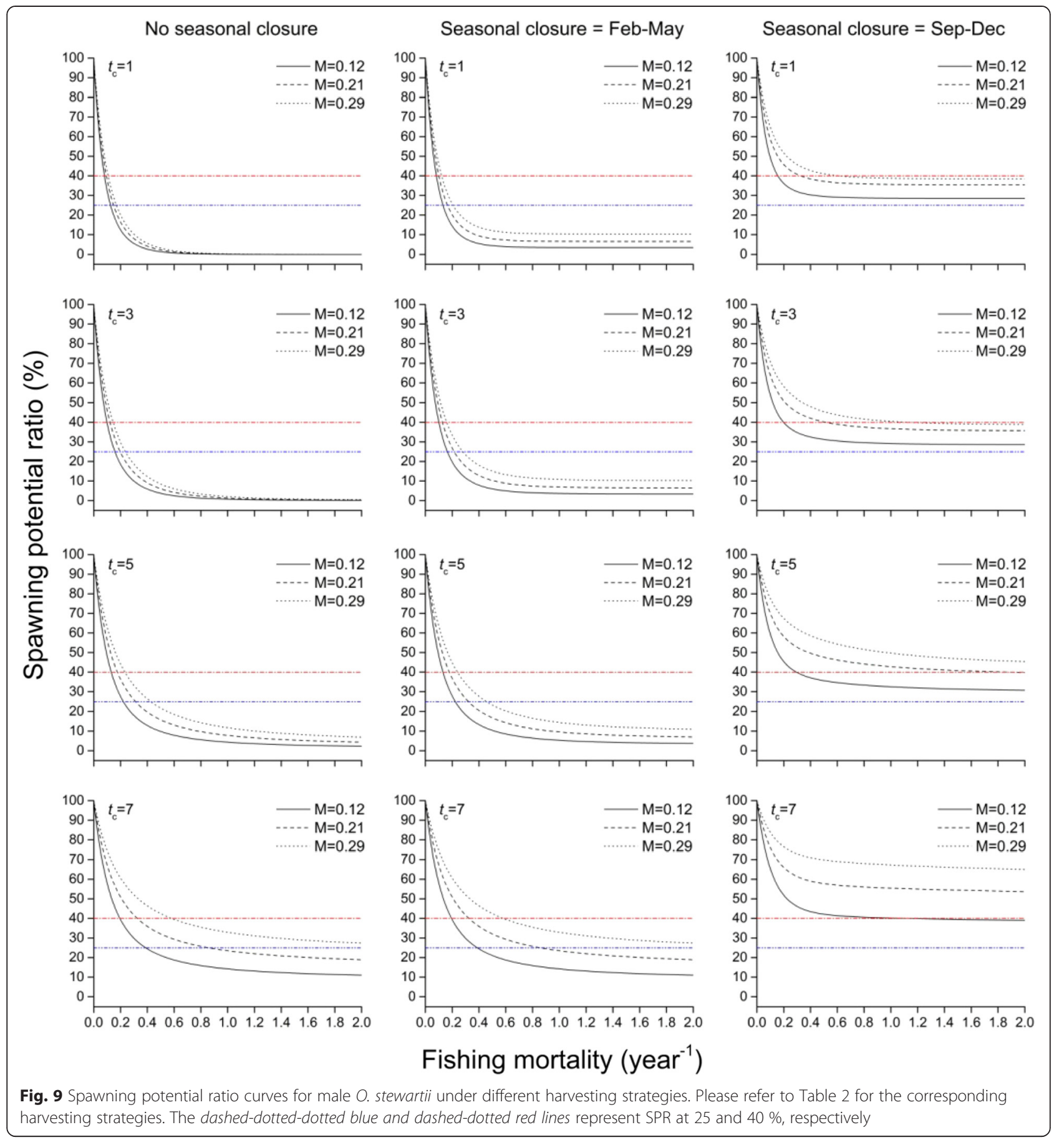

Fifthly, catch curve analysis can be used to estimate the current fishing mortality (derived from $Z$ ) under the assumption that all fish are equally vulnerable to the fishing gear above some determined age. This assumption is often not satisfied in many fisheries, particularly gill net fisheries, due to size selectivity effects of the mesh size. Due to lack of fishing gear selectivity data, the gear selectivity is assumed to be a knife-edge selection in our per-recruit analysis. However, it is clear from the catch curve analysis that size selectivity does exist in the old age groups of O. stewartii fishery, indicating that the estimated $F_{\text {current }}$ may be negatively biased. Moreover, the estimated $F_{\text {current }}$ may also be negatively biased using the weighted regression method proposed by Smith et al. (2012). Overall, our estimate of $F_{\text {current }}$ may therefore be underestimated and should be viewed with caution. Finally, although the stock status of $O$. stewartii is sensitive to the estimated values of $M$, the effects of increasing the age at first capture and introducing 
the closed season are insensitive to the values of $M$, indicating that both of measures can effectively prevent the $O$. stewartii population collapse.

Our results showed that the estimated $F_{\text {current }}$ for males was two times higher than that for females. Generally, females may prefer to be captured, given that females actually grow to a larger size. However, for the fisheries using gill nets, small fish can pass through the meshes as is the case for trawl nets, while large fish may also avoid being caught in a gill net, because their heads are so large that they cannot be gilled (Sparre and Venema 1998). Thus, the $F_{\text {current }}$ for males was estimated using higher age groups than that for females, indicating that the phenomenon that our estimation of $F_{\text {current }}$ for males was higher than that for females may be reasonable.

O. stewartii belongs to the subfamily Schizothoracinae, which originated from primitive barbine fishes distributed in Tibet during the late Tertiary and subsequently evolved into the Qinghai-Tibet plateau fish fauna owing to the vicariance induced by the uplift of Tibet (Cao et al. 1981; Wu and Tan 1991; He and Chen 2006; He and Chen 2007). The isolation made this specialized fish fauna, including $O$. stewartii, more vulnerable to anthropogenic activities. Moreover, $O$. stewartii is the top predator inhabiting the Yarlung Zangbo River (Huo et al. 2014) and changes in its abundance can alter ecosystem processes and community structure in aquatic ecosystems (McQueen et al. 1989; Carpenter and Kitchell 1993; Schindler et al. 1997). Thus, knowledge of the population dynamics of this species is of fundamental importance to conserving this stock. Our findings indicate that the stock of $O$. stewartii is likely to be in the near full exploitation under the current harvesting strategy, and both measures of increasing the age at first capture and introducing the closed season can be effective to protect the O. stewartii population. Our study represents an important investigation in better understanding the population dynamics of this species and its possible management policies within the Yarlung Zangbo aquatic ecosystem. Although our study characterized the likely stock status of $O$. stewartii over a wide range of harvesting strategies using the per-recruit model, we were unable to estimate the age-specific abundance and biomass of the $O$. stewartii population. More research work is needed to fill this information gap for O. stewartii.

\section{Conclusions}

We have, for the first time, quantitatively evaluated the population dynamics of $O$. stewartii. Our results revealed that the stock of $O$. stewartii may be in near full exploitation under the current harvesting strategy, with a high chance of recruitment failure in the future. Although both minimum age limits and seasonal closure could be effective measures to conserve the $O$. stewartii stock, we proposed a seasonal closure to be implemented each year from September to December. Our study represents a first step in better understanding the population dynamics of this species as well as its possible management policies in the Yarlung Zangbo aquatic ecosystem.

\section{Competing interests}

The authors declare that they have no competing interests.

\section{Authors' contributions}

$\mathrm{BH}$ and $\mathrm{CXX}$ conceived and designed the study. BH, BSM, YJD, XFY, and $\mathrm{HPH}$ performed the experiments and acquired the data. BH analyzed the data and performed the statistical analysis. BH prepared the manuscript. BSM and YJD edited the manuscript. CXX reviewed the manuscript and guaranteed the integrity of the entire study. All authors read and approved the final manuscript.

\section{Acknowledgements}

We are grateful to Xin Yang for his assistance and cooperation in carrying out the present study. This study is funded by the special project of the Ministry of Agriculture of the People's Republic of China (201203086).

\section{Author details}

${ }^{1}$ College of Fisheries, Huazhong Agricultural University, Wuhan, Hubei 430070, China. ${ }^{2}$ Yangtze River Fisheries Research Institute, Chinese Academy of Fishery Sciences, Wuhan, Hubei 430223, China.

Received: 20 September 2014 Accepted: 8 June 2015

Published online: 29 July 2015

\section{References}

Arendse CJ, Govender A, Branch GM (2007) Are closed fishing seasons an effective means of increasing reproductive output? A per-recruit simulation using the limpet Cymbula granatina as a case history. Fish Res 85:93-100

Beverton RJH, Holt SJ (1957) On the dynamics of exploited fish populations. In: Fishery Investigations Ministry of Agriculture and Food (Great Britain), vol 2., p 533

Cailliet GM, Goldman KJ (2004) Age determination and validation in chondrichthyan fishes. In: Carrier J, Musick JA, Heithaus M (eds) The biology of sharks and their relatives. CRC Press, New York, pp 399-447

Cao WX, Chen YY, Wu YF, Zhu SQ (1981) Origin and evolution of schizothoracine fishes in relation to the upheaval of the Xizang Plateau. In: Tibetan Expedition Team of the Chinese Academy of Science (ed) Studies on the period, amplitude and type of the uplift of the Qinghai-Xizang Plateau. Science Press, Beijing, pp 118-130, in Chinese

Carpenter SR, Kitchell JF (1993) The trophic cascade in lakes. Cambridge University Press, Cambridge

Chen YF, Cao WX (2000) Schizothoracinae. In: Yue PQ (ed) Fauna sinica osteicthtyes cypriniformes III. Scince Press, Beijing, pp 273-388 (In Chinese)

Cowley PD, Brouwer SL, Tilney RL (2002) The role of the Tsitsikamma National Park in the management of four shore-angling fish along the south-eastern Cape Coast of South Africa. S Afr J Mar Sci 24:27-35

Dichmont CM, Butterworth DS, Cochrane KL (2000) Towards adaptive approaches to management of the South African abalone Haliotis midae fishery. S Afr J Mar Sci 22:33-42

Gabriel WL, Sissenwine MP, Overholtz WJ (1989) Analysis of spawning stock biomass per recruit: an example for Georges Bank haddock. N Am J Fish Manage 9:383-391

Goodyear CP (1993) Spawning stock biomass per recruit in fisheries management: foundation and current use. In: Smith SJ, Hunt JJ, Rivard D (eds) Risk evaluation and biological reference points for fisheries management, vol 120, Can Spec Pub Fish Aquat Sci., pp 67-81

Govender A, Al-Oufi H, Mcllwain JL, Claereboudt MC (2006) A per-recruit assessment of the kingfish (Scomberomorus commerson) resource of Oman with an evaluation of the effectiveness of some management regulations. Fish Res 77:239-247

Griffiths MH (1997) The application of per-recruit models to Argyrosomus inodorus, an important South African sciaenid fish. Fish Res 30:103-115

Griffiths MH (2000) Long-term trends in catch and effort of commercial linefish off South Africa's Cape province: snapshots of the 20th century. S Afr J Mar Sci 22:81-110 
Hauck M, Sweijd MA (1999) A case study of abalone poaching in South Africa and its impact on fisheries management. ICES J Mar Sci 56:1024-1032

He DK, Chen YY (2006) Biogeography and molecular phylogeny of the genus Schizothorax (teleostei: Cyprinidae) in China inferred from cytochrome $b$ sequence. J Biogeogr 33:1448-1460

He DK, Chen YY (2007) Molecular phylogeny and biogeography of the highly specialized schizothoracine fishes. Chin Sci Bull 52:303-312 (in Chinese)

Hildén M (1993) Reference points for fisheries management: the ICES experience. Can Spec Publ Fish Aquat Sci 120:59-66

Huo B, Xie CX, Ma BS, Yang XF, Huang HP (2012) Age and growth of Oxygymnocypris stewartii in the Yarlung Zangbo River, Tibet, China. Zool Stud 51:185-194

Huo B, Xie CX, Ma BS, Yang XF, Huang HP (2013) Reproductive biology of Oxygymnocypris stewartii in the Yarlung Zangbo River in Tibet, China. Environ Biol Fish 96:481-493

Huo B, Xie CX, Madenjian CP, Ma BS, Yang XF, Huang HP (2014) Feeding habits of an endemic fish, Oxygymnocypris stewartii, in the Yarlung Zangbo River in Tibet, China. Environ Biol Fish 97:1279-1293

Hutchings K, Lamberth SJ (2002) Catch-and-effort estimates for the Gillnet and Beach-seine fisheries in the Western Cape, South Africa. S Afr J Mar Sci 24:205-225

Kirchner CH (2001) Fisheries regulations based on yield-per-recruit analysis for the linefish silver kob Argyrosomus inodorus in Namibian waters. Fish Res 52:155-167

Leaman BM (1993) Reference points for fisheries management: the western Canadian experience. Can Spec Publ Fish Aquat Sci 120:15-30

Mace PM (1994) Relationships between common biological reference points used as thresholds and target of fisheries management strategies. Can J Fish Aquat Sci 51:110-122

Mace PM, Sissenwine MP (1993) How much spawning per recruit is enough? Can Spec Publ Fish Aquat Sci 120:101-118

McQueen DJ, Johannes MRS, Post JR, Stewart TJ, Lean DRS (1989) Bottom-up and top-down impacts on freshwater pelagic community structure. Ecol Monogr 59:289-309

Myers RA, Worm B (2003) Rapid worldwide depletion of predatory fish communities. Nature 423:280283

$\mathrm{Ng} \mathrm{HH}$ (2010) Oxygymnocypris stewartii. IUCN Publishing Red List of Threatened Species., http://www.iucnredlist.org/details/168408/0. Accessed Apr 2010

Pauly D, Christensen V, Guénette S, Pitcher TJ, Sumaila UR, Walters CJ, Watson R, Zeller D (2002) Towards sustainability in world fisheries. Nature 418:689-695

Pradervand P, Baird D (2002) Assessment of the recreational linefishery in selected Eastern Cape estuaries: trends in catches and effort. S Afr J Mar Sci 24:87-101

Quinn TJ II, Deriso RB (1999) Quantitative fish dynamics. Oxford University Press, New York, pp 1-542

Ricker WE (1975) Computation and interpretation of biological statistics of fish populations. Bull Fish Res Bd Can 191:1-333

Rivard D, Maguire JJ (1993) Reference points for fisheries management: the eastern Canadian experience. Can Spec Publ Fish Aquat Sci 120:31-58

Schindler DE, Carpenter SR, Cole JJ, Kitchell JF, Pace ML (1997) Influence of food web structure on carbon exchange between lakes and the atmosphere. Sci 277:248-251

Smith MW, Then AY, Wor C, Ralph G, Pollock KH, Hoenig JM (2012) Recommendations for catch-curve analysis. N Am J Fish Manag 32:956-967

Sparre P, Venema SC (1998) Introduction to tropical fish stock assessment. Part 1. Manual. FAO fisheries technical paper. No. 306. 1, Rev. 2. FAO, Rome

Sun CL, Wang SP, Porch CE, Yeh SZ (2005) Sex-specific yield per recruit and spawning stock biomass per recruit for the swordfish, Xiphias gladius, in the waters around Taiwan. Fish Res 71:61-69

Taylor CC (1958) Cod growth and temperature. J Cons Int Explor Mer 23:366-370

Then AY, Hoenig JM, Hall NG, Hewitt DA (2014) Evaluating the predictive performance of empirical estimators of natural mortality rate using information on over 200 fish species. ICES J Mar Sci 72(1):1-6

Turpie JK, Beckley LE, Katua SM (2000) Biogeography and the selection of priority areas for conservation of South African coastal fishes. Biol Conserv 92:59-72

Wu YF, Tan QJ (1991) Characteristics of the fish-fauna of the characteristics of Qinghai-Xizang plateau and its geological distribution and formation. Acta Zool Sin 37:135-152

Wu YF, Wu CZ (1992) The fishes of the Qinghai-Xizang Plateau. Sichuan Publishing House of Science \& Technology, Chengdu (In Chinese)

Ye Y (1998) Assessing effects of closed seasons in tropical and subtropical penaeid shrimp fisheries using a length-based yield-per-recruit model. ICES J Mar Sci 55:1112-1124

\section{Submit your manuscript to a SpringerOpen ${ }^{\odot}$ journal and benefit from:}

- Convenient online submission

- Rigorous peer review

- Immediate publication on acceptance

- Open access: articles freely available online

- High visibility within the field

- Retaining the copyright to your article

Submit your next manuscript at $>$ springeropen.com 